\title{
Diagnostic Cieux
}

\author{
Eva Jaeggi
}

Psychotherapie-Wissenschaft 8 (1) 17-18 2018

www.psychotherapie-wissenschaft.info

CC BY-NC-ND

DOI: $10.30820 / 8242.02$

Mots-clés : Enseignement psychanalytique du développement ; compromis ; psychanalyse relationnelle ; psychologie humaniste

Lorsqu'on observe en tant que vision fantasmagorique les représentations toutes différentes de religions et cultures diverses concernant l'au-delà, on peut également essayer de catégoriser ces " rêves » par des termes psychanalytiques, ce qui correspond à une sorte de « diagnostic » de ces représentations des " cieux ", tel qu'ils sont désignés dans l'usage linguistique chrétien. Les rêves de cieux disent donc quelque chose sur un collectif, qui traite certains thèmes universels. Dans certaines régions et cultures, l'au-delà n'est toutefois pas impérativement associé à un état " complètement différent ». Les trousseaux funéraires dans l'antiquité ou dans les tribus germaniques par exemple indiquent que cela se déroule bien de la même façon dans l'au-delà que dans le présent : on a besoin de suffisamment de nourriture, de bijoux et de vêtements afin de pouvoir représenter quelque chose aussi là-bas. Les " chasses éternelles " de certaines tribus indiennes ne semblent pas très éloignées non plus des joies terrestres. Si l'au-delà est imaginé toutefois comme un "autre ", alors les désirs (et également dissimulés les conflits) d'une certaine culture émis par tous les hommes semblent émerger d'une manière plus manifeste que dans ces fantasmes terrestres. Il est alors possible d'utiliser par ex. les trois niveaux de développement (et avec : les conflits) faisant partie de l'enseignement freudien du développement en tant que structure hypothétique, afin de catégoriser différents types de représentations des cieux. Au niveau œdipien - ou : exprimé d'une manière plus moderne : le niveau auquel nourrir ou être nourri est un thème central, il est possible de classifier toutes les représentations de l'au-delà dans lesquelles l'homme n'est plus que comblé. Cela peut être des univers merveilleux (le «Jérusalem divin »), une multitude d'aliments comme dans de nombreuses descriptions de l'au-delà musulman ou également la sexualité sans effort - comme présent pour lequel il n'est pas nécessaire de faire quoi que ce soit. Le conflit qui crée si souvent des problèmes dans l'existence terrestre est résolu : on est nourri comme le petit enfant. On vit en quelque sorte d'une manière ludique, avec de la musique et un bonheur durable. Cela sert également de référence au Pays de Cocagne. Le prochain niveau de développement **anal " dans la psychologie freudienne (à savoir : la recherche de l'indépendance opposée au besoin de soutien) se manifeste dans les représentations de mouches, de fantaisies naïves d'anges, de liberté de l'apesanteur. Toute une série de sectes ésotériques en fait également partie. Le troisième niveau (« œdipien ») se révèle dans des images qui illustrent l'amour inconditionnel, l'union avec nos familles sans discorde et rivalité. Un imaginaire de fusion est parfois également présent. Augustin, dont la sexualité lui a notoirement apporté de gros problèmes, imagine la relation des sexes sans sexualité.

Non plus représentée d'une manière iconographique, mais plutôt formulée dans un langage théologique abstrait, il serait possible de faire coïncider des développements de la psychanalyse (ou également de la psychologie humanistique) surtout avec la 13e lettre aux Corinthiens de Saint-Paul. L' " être vu » par Dieu, la connaissance de l'autre ainsi que la connaissance rendue possible de la propre personne, est thématisé. C'est exactement cela que la psychanalyse relationnelle et la psychologie Humanistique considèrent comme le sujet principal de la "guérison ». Les thérapeutes humains ne peuvent toutefois jamais promettre la «guérison » définitive, on fait appel ici à la théologie. Par ailleurs, Saint-Paul montre d'une manière étonnamment clairvoyante la direction qu'il faut suivre pour approcher les hommes de la guérison. C'est le dialogue dans lequel la reconnaissance est considérée comme un processus dialectique. Il serait possible de voir dans la guérison le troisième niveau du processus dans lequel il est reconnu que nous pouvons, à partir d'antithèses (nourrir - être nourri ; être libre versus la dépendance ; amour sans haine) à traverser encore et encore, nous élever vers la troisième étape de l'abrogation de ces conflits. Il y a ensuite le niveau dans lequel nous ne faisons pas seulement espérer et croire, mais aimer : L'amour qui intègre tout et qui promet par la connaissance extrême également la guérison complète, dans l'amour humain, nous sommes le plus près de l'amour divin.

Bien sûr, il est impossible de vérifier cette observation de la représentation de l'au-delà, cela n'est jamais possible dans l'analyse de visions culturelles. Dans la psychanalyse, chaque diagnostic (également celui qui va au-delà des rêves) est en effet posé uniquement en lien avec toute l'histoire de vie d'un individu. Il n'existe pas, justement avec les rêves, de significations fixes à déterminer, mais uniquement des thèmes, problèmes importants induits des associations du rêveur et des besoins centraux à 
exclure. Lorsque nous « diagnostiquons » de cette façon des sujets préformés culturellement, il reste évidemment toujours une faille. Toutefois, nous connaissons justement d'autres orientations de chaque culture, qui rendent plausibles l'hypothèse que des situations généralement humaines de besoin et de conflit jouent aussi un rôle dans les représentations de l'au-delà. Il est tout à fait possible de les rendre plausibles avec des catégories psychanalytiques.

\section{L'auteure}

Eva Jaeggi, em. Prof. de Psychologie Clinique, est psychanalyste et thérapeute comportementale, par ailleurs auteure de nombreux ouvrages et articles (entre autres comparatif d'écoles de thérapie, formes de vie moderne, profession du thérapeute, âge).

\section{Contact}

Eva.Jaeggi@tu-berlin.de 